\title{
Geostatistics - A Tool to Map Thin Reservoirs
}

\section{Derksen $\mathbf{R}$}

Rohöl - Aufsuchungs - A. G., Austria

Copyright 1995, Steering Committee of the European tOR - Symposium.

This paper was presented at the 8th. European IOR - Symposium in Vienna, Austria, May 15 - 17, 1996

This paper was selected for presentation by the Steering Committee, following review of information contained in an abstract

submitted by the author(s). The paper, as presented has not been reviewed by the Steering Committee.

\section{Abstract}

The Munderfing gasfield in the Upper Austrian molasse basin consists of Lower Miocene turbidite sands reworked in a deep ocean bottom channel system. Net thicknesses of sands vary from 0 to $8 \mathrm{~m}$ in as many as 10 individual layers over an interval of $150 \mathrm{~m}$. Historically, the minimal thickness of these bodies and complex stratigraphy have prevented mapping of the packages. Recent experience with a multidisciplinary approach involving geostatistics and seismic attribute analysis (along with geologic and engineering data) offers the potential of changing this situation. This paper will discuss the data preparation, the geostatistical analysis and the final map evaluation procedures that RAG is currently using in this environment.

\section{Introduction}

I would like to present a case study in the use of seismic attributes and geostatistics to delineate thin gas sands in a producing field. This is a new approach for us and attempts to incorporate geophysics, geology and engineering data to map and to subsequently validate these results. Conventional interpretation and mapping techniques have been unable to image more than the structure associated with the sand bodies.

\section{Location}

The Munderfing gas field is located about 30 kilometers northeast of Salzburg in the middle of the Molasse foreland basin. It produces gas from the Miocene Hall Formation. The reservoirs are fine to medium grained turbidite sands deposited in a NW/SE trending submarine channel feature at the Miocene/Oligocene unconformity. This feature is 3 to 4 kilometers wide and extends for a distance of over 15 kilometers. The gas is trapped in an WNW/ESE trending anticline caused by differential compaction within the underlying Oligocene coarse clastics. The resulting gas accumulation is thus a combination of stratigraphic and structural control (fig. 1).

- This channel fill has a maximum thickness 


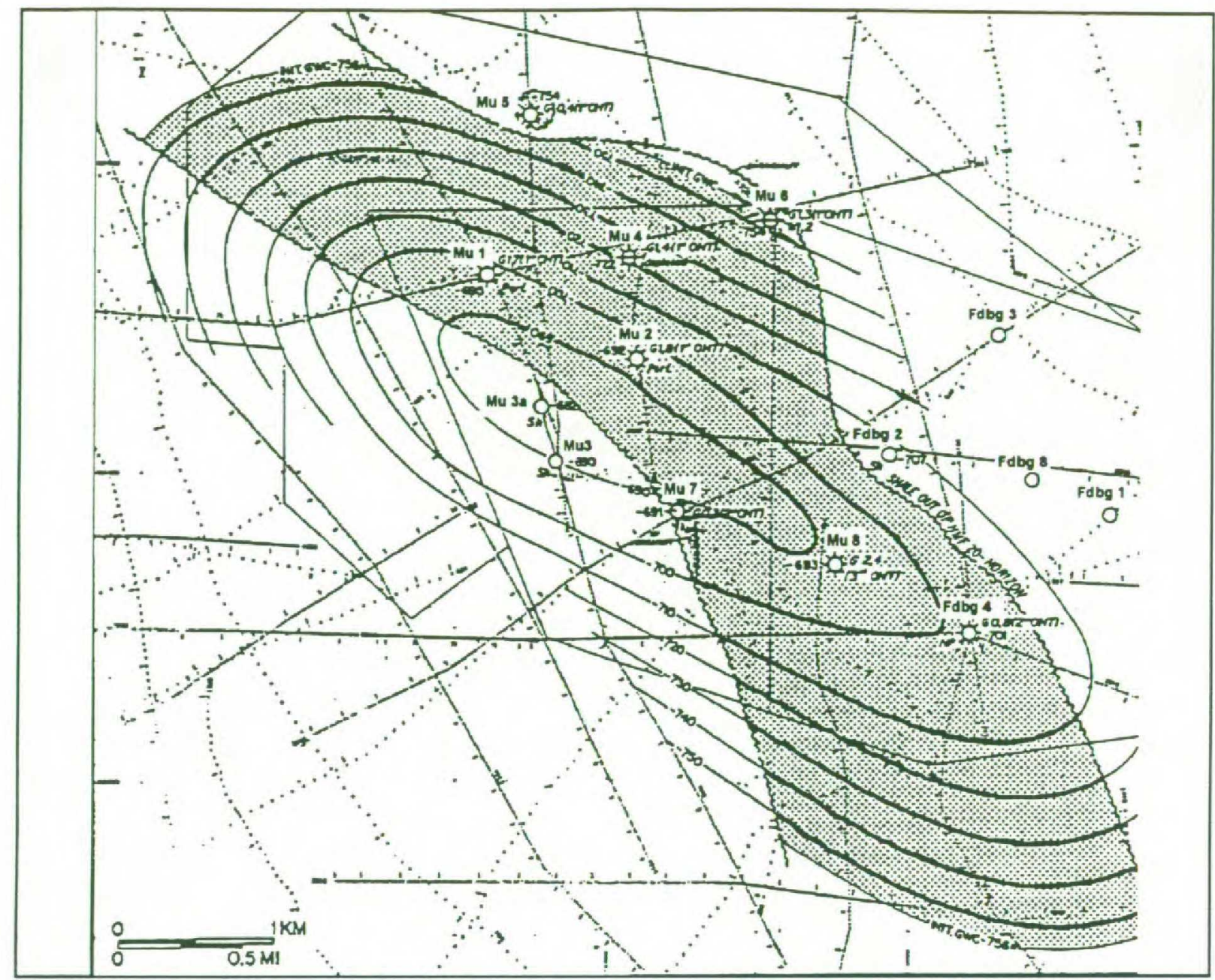

Fig. 1. Munderfing gas field. Depth structure map of top HMF 20 horizon, status: pre-3D.

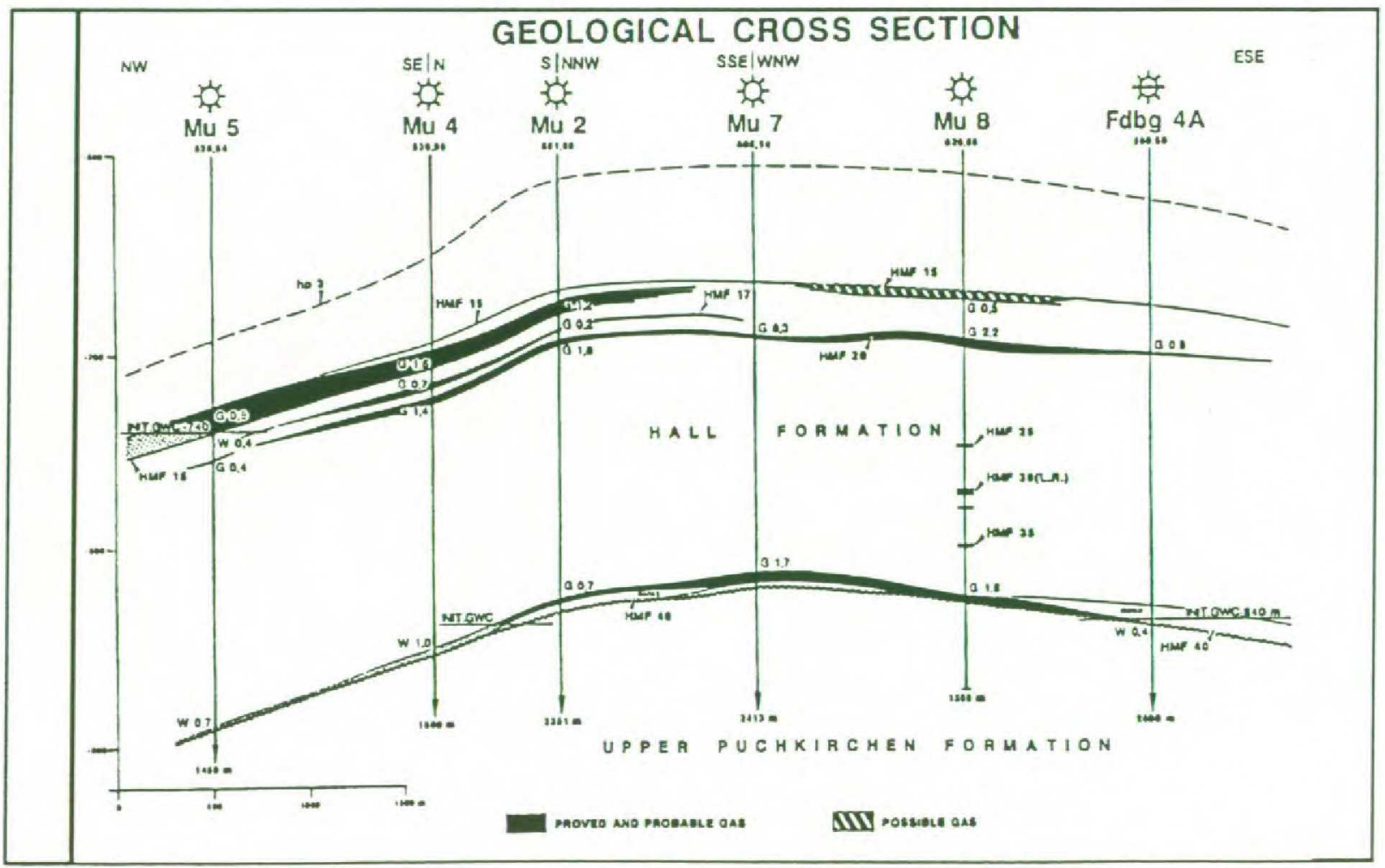

Fig. 2 Simplified geologic cross section of basal Miocene channel fill (sand thickness exaggerated) 
of $150 \mathrm{~m}$ at the centre of the feature. The lithology is primarily composed of silty shales. Slumping has occurred extensively (may be dominant) and very low velocity, reworked shales moving in from the north are the primary seismic reflector within this sequence. The turbidite sands are very thinbedded (less than 2 meter max., typically less than 1 metre) with a complex distribution and inter-relationship.

The primary producing zones are the HMF 15-20 sands at the top of the sequence (depth $1250 \mathrm{~m}$, time $700 \mathrm{msec}$ ) and the HMF 40 basal sands at the Miocene/Oligocene unconformity. The basal sands are widely and relatively uniformly distributed throughout the field. The top sands are less uniformly distributed and demonstrate only fair to poor communication with one another. Sands have also been encountered in the middle of this section, but have tended to be of limited extent and have not contributed much to the reserves.

Cumulative production to end 1994 has been 509 MMcbm (19 bcf) of sweet gas. Pressure and production studies have indicated considerable reserve potential not previously defined.

A 3D seismic survey was acquired to further detail the area and geostatistics were employed in an attempt to define reservoir distribution within the structural outlines.

\section{Seismic Resolution}

The goal was to map very thin sands in a stratigraphic regime with a lot of geologic "noise" or variation. The target sands are, individually, no more than $2 \mathrm{~m}$ thick. Maximum net sand in the entire basal sequence is $8 \mathrm{~m}$ in more than 15 individual layers.

These sands exhibit a porosity of about 30 $\%$, a permeability of about $300 \mathrm{mD}$. and, when gas charged, have a velocity in the order of $2800 \mathrm{~m} / \mathrm{sec}$ (in a silty matrix of
$3800 \mathrm{~m} / \mathrm{sec}$ ). These targets should be good reflectors, except their thickness is well within the thin-bed linear tuning range of our $80 \mathrm{~Hz}$ seismic information. Whatever response they have is further masked by the presence of slumped, reworked shales that have velocities of less than $2500 \mathrm{~m} / \mathrm{sec}$ and thicknesses of $10 \mathrm{~m}$ or more. Where present, these slumps dominate the seismic response and we have been historically unable to identify or map a sand contribution to the seismic response using 2D data.

The traditional approach would be to model the geology and then proceed to map on the basis of these results. However, the thinbedded nature of our deep marine sequence is well inside the tuning zone of our seismic wavelet. This requires the careful location of many individual layers in order to build up a reasonable model thickness. The turbidite/slump dominated stratigraphy also makes for high vertical as well as horizontal variability. The potential number of permutations and combinations that could (or should) be modelled is daunting. As a result, modelling has not been an effective tool.

Indirect mapping of geologic parameters is not a new concept. Seismic energy within a time window has been used to map pay thickness in a turbidite regime with success in other areas. A simple study was initiated to discover if a similar relationship between seismic amplitudes and sand deposition could be found in the Munderfing field. A simple model demonstrates the concept. Should the channel fill be entirely of silty shales, there are reflections from only top and bottom and the channel fill itself is reflection free. The average energy in this window will be low. This is illustrated in figures 3 and $3 \mathrm{a}$. 


\section{Mu 4 SONIC MODELS}

MODEL ORIGINAL

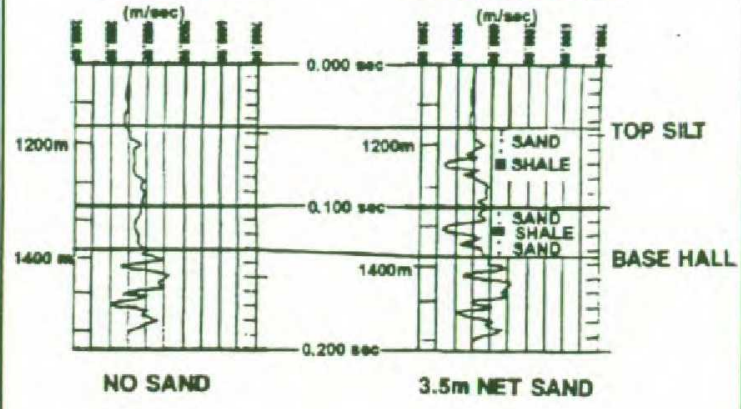

Fig. 3 Simple sonic log model showing influence of lithology variation.

In fig. 3, the sands and low velocity shales have been removed; fig. $3 \mathrm{a}$ then demonstrates the change in net seismic energy that results. Subsea erosion (among other processes) creates topographic lows in which turbidite sands are preferentially deposited. Turbidites are themselves a force of erosion. Slumping is also intimately related to erosion and subsea topography development. Any relationship between sand and average energy cannot, thus, be perfect. However, average energy is an effective measure of lithologic variability in the channel fill and sand is one of the elements involved in this variability.

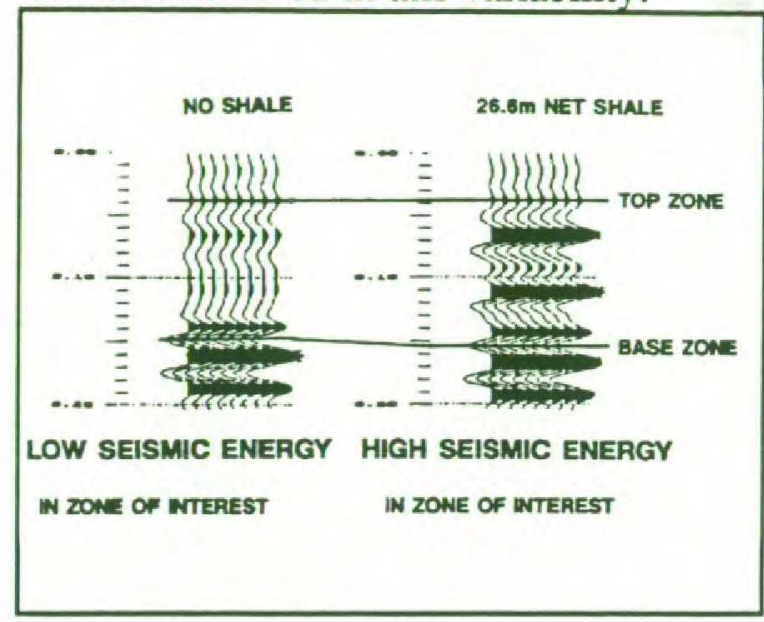

Fig. 3a Seismic model derived from fig. 3. Note difference in seismic energy.

Fig.4 demonstrates the spreadsheet graph that was used to map the net sand in the Hall basal sequence. The vertical axis is the average absolute amplitude of the seismic trace between the top and the base of this unit. The horizontal axis is the total net sand found within this same zone. Only those wells were used that had encountered at least some sand. Based on this line of best fit, 6 metres of net sand was predicted at the location of Mu 9 (see fig. 5). This well subsequently penetrated 6.6 metres of sand in the basal sequence. The actual net sand map created using the results of fig. 4

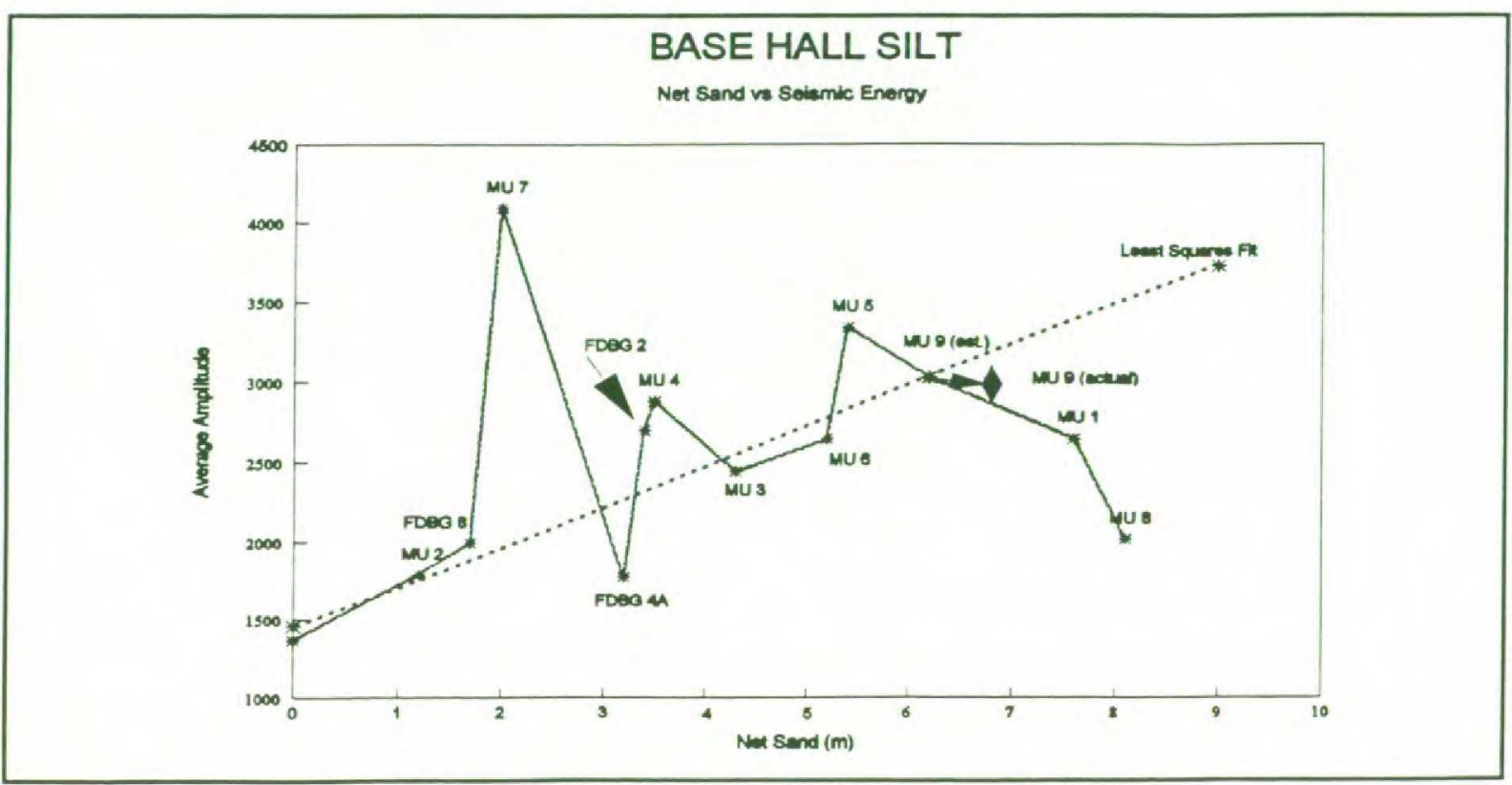

Fig. 4 Graph showing relationship between net sand and average seismic energy. 


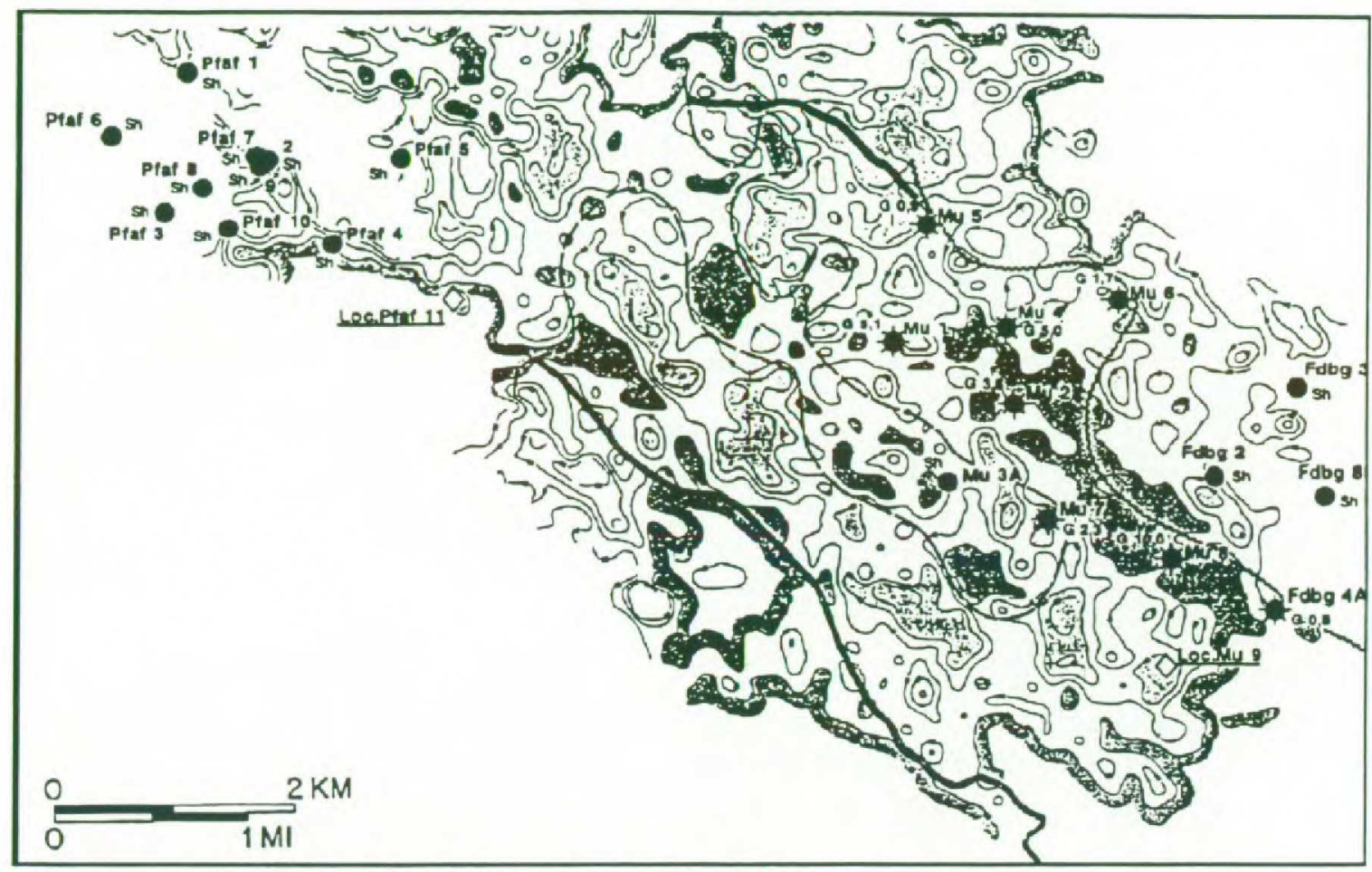

Fig. 5. Total net sand distribution map in basal Hall sequence (1 $\mathrm{m}$ contours).

is shown in fig.5. The dark zones highlight areas of very little sand; the grey areas indicate trends of thicker sand deposition. This map does not show the distribution of individual sands. The pattern of sand deposition that is shown supports the generally patchy nature that production development had indicated.

The well, Munderfing 9 (Mu 9) was drilled and completed as a discovery in the HMF 15-20 producing zones $(1.9 \mathrm{~m}$ net sand/pay). Total sand in the basal complex was 6.6 meters. It is producing at a rate of 125 thousand cubic meters per day (5 mmcf/day). The proved and probable reserves attached to this one producing level have been increased by 590 million cubic meters $(22$ bcf $)$ gas in place. The interpretation has also identified another 490 million cubic meters (18 bcf) of possible resources that have yet to be drilled. One well does (or does not) prove a statistical method like this, but it was sufficient to lead us to pursue the matter further in this field.

\section{Geostatistics}

As the well, Mu 9, was being prepared for drilling, attempts were made to expand on the geostatistical mapping using more sophisticated tools and approaches. The goal was to narrow the focus to the HMF 15 through HMF 20 sands near the top of the basal silt sequence rather than all the sands in the entire zone (fig. 2).

These sands lie in the top 30 metres of the sequence. There may be 1 to 8 individual sand layers with a maximum net of 4 metres. Average individual sand thickness is less than $0.5 \mathrm{~m}$. Though widely distributed in the channel feature, the sands exhibit only poor/fair communication with one another. They can be (relatively) good producers and $1.4 \mathrm{~m}$ net sand can test at over 130,000 cubic meters/day (5 mmcf/day) through a $24 / 64 "$ choke.

The seismic response that encompasses this $30 \mathrm{~m}$ package is a trough at approximately the top of the higher velocity silts and a following peak. One wavelength is all there is to work with; the response of the 
individual sands (gas or water bearing) lies buried within this peak/trough character

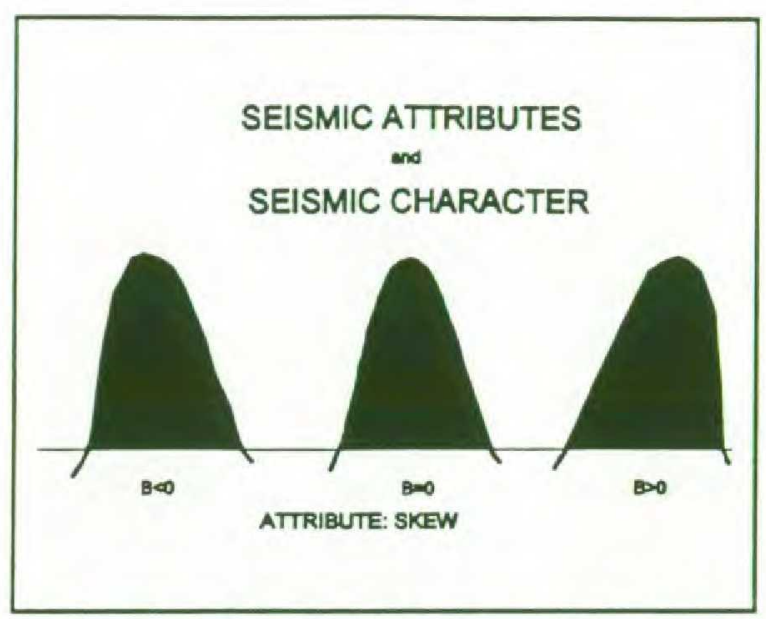

Fig. 6 Relationship between seismic character and statistical attribute, SKEW. only 20 msec. wide.

Tools exist that are capable of analyzing a seismic wavelet in much finer detail than the human eye. We used one such and were able to extract more than 60 seismic attributes from this peak/trough pair. These are real measures of seismic character; some are very subtle. Skew, for example, is defined as the first population moment about the mean. When applied to seismic character, it is a measure of the symmetry of a peak or trough (fig. 6). The procedure began, then, to seek a statistical correlation between these seismic attributes and the

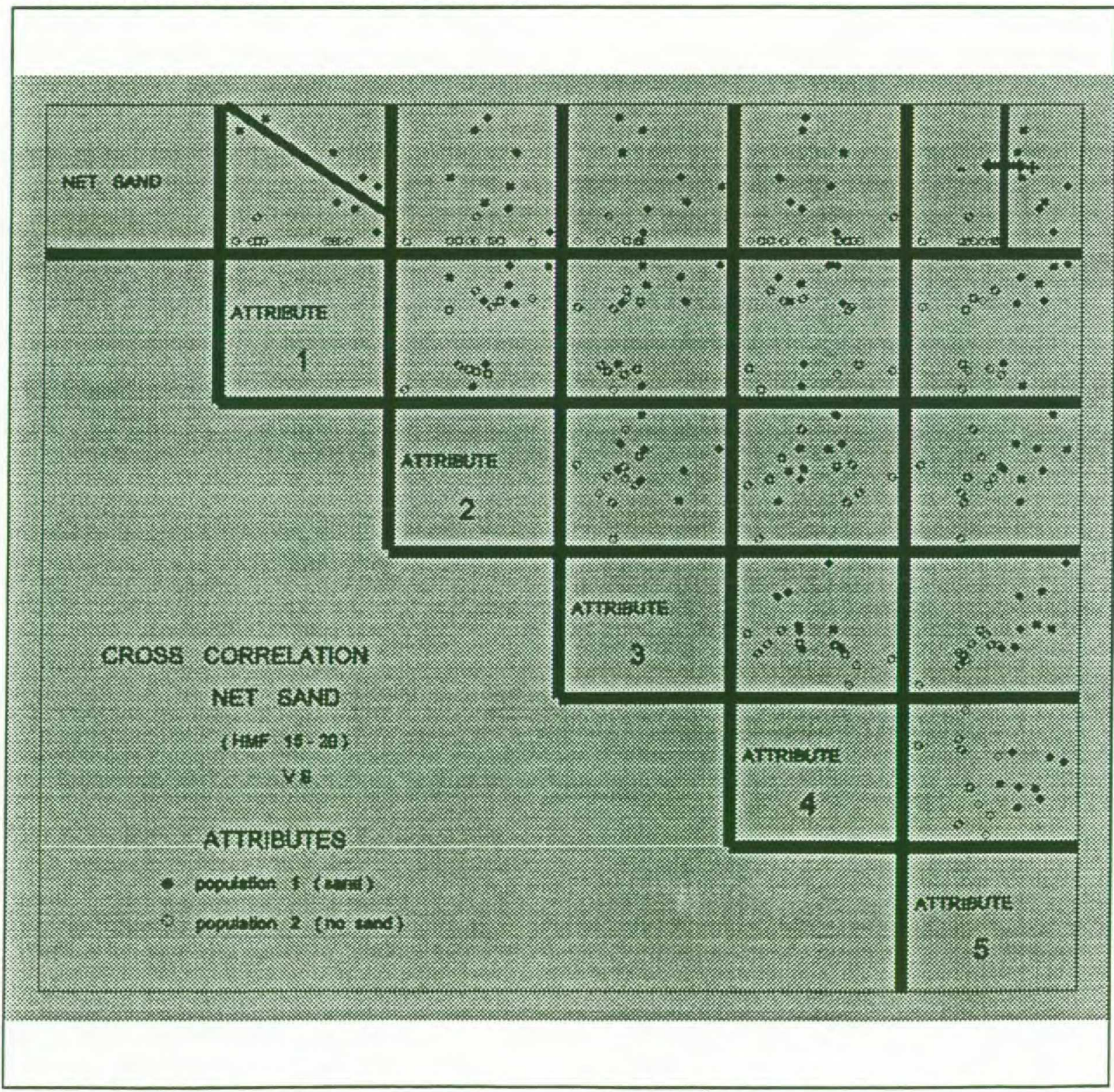

Fig. 7. Crossplot of seismic attributes and net sand. Note linear relationship with Att. 1 and separation made possible with Att. 5. 
geological attributes of interest at well locations. Seventeen well points were available, nine of which had encountered at least some porous sand at HMF $15-20$ levels.

Several seismic attributes were uncovered that demonstrated a strong linear relationship with net sand in the HMF 1520 zone. Fig. 7 shows the crossplots of net sand and the 5 seismic attributes that were used in the final mapping. It became apparent that there were two groups of wells (black dots and white dots). There were wells that showed a strong correlation with net sand (population 2). Attribute 1 has a correlation coefficient of 0.83 when plotted against the net sand values of these wells. There was, however, a second group of wells that showed no relationship whatsoever between net sand and these same seismic attributes. Fortunately, this population 2 had, generally, no (or very little) sand at the zone of interest. The primary problem became to separate population 1 (locations where the linear function could predict sand) from population 2 (locations where no correlation between sand and seismic attribute could be found). In short, population 1 has sand, population 2 has none and how can you tell the difference (before drilling)?

No single seismic attribute could be found that was capable of separating these two polulations. A process called discriminant analysis, however, looks for combinations of attributes that allow sorting into groups. A combination of 3 attributes (2, 3 and 4 in fig. 7) was found that successfully separated well locations with sand from those without. This combination is shown as attribute 5 . It is calculated strictly from seismic attributes and any point that is negative belongs to population 2 , while a positive value belongs to population 1 . It is important to note that all the seismic attributes (1 through 5) do not correlate well with one another. This indicates that they are independent measures of some physical characteristic.

The mapping was done in two steps. First, attribute 5 was calculated throughout the entire survey area from the seismic. The areas where the value was negative indicated no sand and all these points were removed. At the data points that remained, the correlation with seismic attribute 1 was used to estimate net sand. This map is

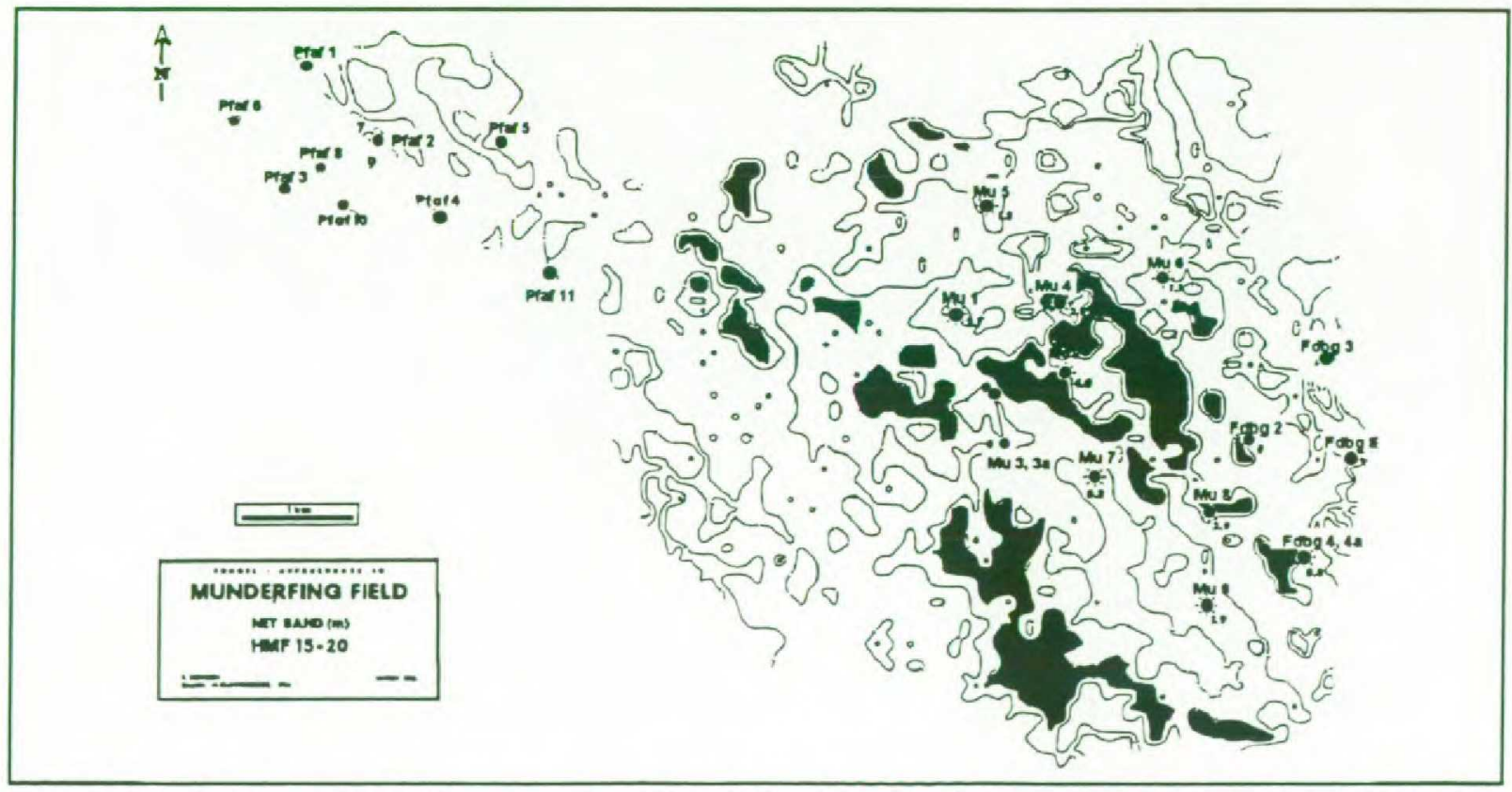

Fig. 8 Final net sand distribution map, HMF $15-20$. Sand thicks $(>2 \mathrm{~m})$ are highlighted in black ( $1 \mathrm{~m}$ contours). 
shown in fig. 8 .

\section{Map Evaluation}

The map of these very thin sand bodies that has been produced using well information and seismic character is shown in fig. 8. All the available data was used; there was little opportunity for user bias to influence the final results. The statistical measures of such things tell us that the results are "significant", in spite of having only 17 control points. A cross validation error analysis (subtracting the true from the estimated net sand values at each control point) indicated an average absolute error of less than 0.6 metres. There has been no analysis of cause and effect to this point, only apparent relationships have been identified. How much significance should we give this map when it comes time to finding future well locations?

When viewed from a geological perspective, the map is both stable and plausible. This means that:

a) the values of net sand cluster between 0 and 4 metres, even in areas beyond well control. This is the range that is expected.

b) there are patterns of sand distribution demonstrated. The trend directions (NW/SE) parallel the deep water currents known to have been present at time of deposition.

Engineering data was used to evaluate this map as well. Many separate sand bodies are indicated; the sands are known to be in poor communication with one another. Mu 9 was completed as this part of the study was still underway. It encountered $1.9 \mathrm{~m}$ net gas sand at original reservoir pressure, i.e. none of the other producing wells in the field were depleting this sand. The map indicates that the nearest wells are tapping distinctly different sand trends.

Any map based on a concept is better than no map at all. It promotes discussion; challenges the concepts and presumptions that were incorporated into it's making. It makes predictions. In this case, the whole western half of the channel fill has been made prospective. It releases some of the constraints that structure had previously imposed on potential well location and demonstrates the necessity of a better understanding of the stratigraphic processes that have controlled this sand deposition. The trick is to know how much better the map is (than no map at all).

So, what has been mapped and why do the maps look so good? I do not believe that even the use of subtle seismic character attributes is allowing us to resolve sands only $0.5 \mathrm{~m}$ thick. Rather, I think that these attributes are reacting to a larger, thicker stratigraphic package that contains, these sands. Central to this is the concept that whatever geologic processes influenced the deposition of any particular thin turbidite sand body were also operational prior to and continued after this single stratigraphic event. These sands were not randomly distributed in total isolation from one another or the other lithologic units found in this zone.

\section{Conclusion}

After completion of this study, another well, Pfaf 11 was drilled to a deeper primary target. It penetrated 65 meters of the basal Hall silts, but only $1 \mathrm{~m}$ of tight sands at the HMF 15 - 20 level. This agreed with the attribute map predictions. In 1996, two well locations are planned to test the sand distribution in the western part of the channel feature. These wells will not be located on structural highs; but will further investigate the stratigraphic features that this case study has identified.

Independently, we are attempting to continue and expand this work. The concept of a stratigraphic package will have to be studied and defined as a precursor to 
modelling. This will help to establish a causal relationship between the seismic attributes, the statistics and the geology in this gas field. Work is also continuing to better establish a tectonic framework which has influenced the stratigraphy and produceability of the gas fields in this area.
I would like to thank my colleagues at RAG for the help, advice and work that was generously given and made this paper possible. My thanks as well to RAG and shareholder management for allowing me to present this project. 